\title{
Purchasing a cycle helmet: are retailers providing adequate advice?
}

\author{
Elizabeth Plumridge, Judith McCool, Jane Chetwynd, John D Langley
}

\begin{abstract}
Objectives-The aim of this study was to examine the selling of cycle helmets in retail stores with particular reference to the adequacy of advice offered about the fit and securing of helmets.
\end{abstract}

Methods-All 55 retail outlets selling cycle helmets in Christchurch, New Zealand were studied by participant observation. A researcher entered each store as a prospective customer and requested assistance to purchase a helmet. She took detailed field notes of the ensuing encounter and these were subsequently transcribed, coded, and analysed.

Results-Adequate advice for helmet purchase was given in less than half of the stores. In general the sales assistants in specialist cycle shops were better informed and gave more adequate advice than those in department stores. Those who gave good advice also tended to be more active in helping with fitting the helmet. Knowledge about safety standards was apparent in one third of sales assistants. Few stores displayed information for customers about the correct fit of cycle helmets.

Conclusions-These findings suggest that the advice and assistance being given to ensure that cycle helmets fit properly is often inadequate and thus the helmets may fail to fulfil their purpose in preventing injury. Consultation between retailers and policy makers is a necessary first step to improving this situation.

(Injury Prevention 1996; 2: 41-43)

Keywords: cycle helmet, cycle injuries, legislation.

Following a recent change of legislation, cycle helmets are now compulsory in New Zealand for bicyclists of all ages riding on public roads or in public areas. ${ }^{1}$ A recent examination of trends in head injury to bicyclists before the introduction of this law has shown that the percentage of serious head injuries has been relatively constant for all age groups, irrespective of helmet wearing rates. Between 1989 and 1992 , helmet wearing rates increased from $46 \%$ to $84 \%$ for primary schoolchildren, $23 \%$ to $62 \%$ for secondary schoolchildren, and $21 \%$ to $39 \%$ for adults. However, the percentage of serious head injuries among cyclists remained constant for all three groups and did not decline as expected as cycle helmet wearing increased (PA Scuffham, JD Langley, unpublished). It has been suggested that this situation may in part be due to helmets not being the correct fit. It has also been suggested that this may be because the advice given to prospective purchasers of helmets is not always appropriate. ${ }^{2}$

The aim of the research reported here was to examine the exchange surrounding a helmet purchase, with particular reference to the adequacy of advice offered about the fit and securing of the helmet.

\section{Methods}

In Christchurch, the main cycling city in New Zealand, 55 retail outlets selling cycle helmets were studied.

The research was conducted by means of participant observation. A member of the study team (JM) entered each store as a prospective customer and requested assistance in the purchase of a helmet. In addition, she observed the physical layout of the helmets on sale and the advertising and promotional material on display. Immediately after each encounter she dictated detailed field notes and subsequently transcribed and coded them.

In particular the researcher (hereafter referred to as the customer) assessed the adequacy of advice given and the assistance offered with assessment of helmet fit. Advice was judged to be 'adequate' when an assistant:

- Displayed correct knowledge about cycle helmets

- Volunteered relevant information regarding the selection of a correctly fitted helmet

- Took time to explain the range of helmets

- Was familiar with the safety issues regarding current safety standards and construction of the helmet

- Helped the customer with the adjustment of helmet straps and padding

Ability to assess the fit of helmets was judged by whether assistants took actions to check for a correct fit, that is checking for forward and backward movement according to the Land Transport Safety Authority guidelines. ${ }^{3}$

Analysis of the data included frequency counts of the advice given and fit assessments offered. The data collected through detailed field notes were subject to thematic abstracting using the Ethnograph program. ${ }^{4}$ Coding categories were developed by consensus among the research team.

\section{Results}

The stores were classified into specialist cycle shops, either inner city $(n=9)$ or suburban $(n=29)$, and more general department stores $(n=17)$. 
ADVICE AND HELP WITH FIT

In over half of the specialist shops $(21 / 38)$, assistants were thorough and provided an adequate level of quality advice. Those assistants who gave good advice also tended to be more active and spontaneous in assisting with fitting the helmet. This practical assistance with fit of helmet was more common in suburban specialist shops $(10 / 29)$ than in inner city ones $(1 / 9)$. In those shops where advice or help was not adequate (17/38), assistants offered little information and often appeared to be apathetic.

The help from assistants in general/ department stores was not so positive. Only four of 17 assistants were able to provide advice about the correct fitting. Most were only able to give information on the price and range of helmets available. Any advice that was offered in respect to fit tended to be subjective and practical help was rarely offered (3/17).

AWARENESS OF SAFETY STANDARDS AND HELMET CONSTRUCTION

In about one third of the specialist cycle shops $(12 / 38)$ assistants were able and willing to inform the customer on the current safety standards, and were aware of the impending changes to standards, due in 1996. The remainder (22/38) knew nothing of safety standards beyond the identification of a standards approved sticker. In two shops second hand helmets could be purchased. This poses a particular safety hazard as it is uncertain whether the helmets may have developed hairline fractures due to damage in the past.

Assistants saw little difference in construction among the various brands of helmets except for the more expensive variety which has the extra feature of a 'roll cage' as a strengthening inner brace. No assistant suggested that more money spent on a helmet would mean more safety. There was some confusion over the purpose of the plasic cover that shields the polystyrene from excessive friction damage; several assistants misunderstood this and suggested the plastic cover to be no more than a 'cosmetic' extra.

Assistants in the general/department stores showed little knowledge of safety standards or the quality of helmet construction, but all were prompt to assure the customer that every helmet sold in their store met approved safety standards. One chain had a notice displaying this policy in all of its outlets.

LOCATION, PRESENTATION, AND ACCESSIBILITY OF HELMETS

In the majority of the specialist shops there was an absence of advertising material or information about helmets. Helmets tended to be located to the rear of the store and displayed upon shelves or on upright rotating racks. In two shops helmets were enclosed in sealed plastic bags, which acted as a deterrent to trying them on.

In general stores the helmets were often difficult to locate but were most likely to be found in either the sports equipment, child- ren's toys, or household goods area. Again there was no advertising or information available. Overall the range was minimal so the helmet display tended to take up a small amount of space.

\section{SELLING STRATEGIES}

Typical selling strategies revolved around either discussing the style of helmet preferred or its price. Within the suburban specialist shops value for money was considered by many assistants (13/29) to be the most important feature in choice of helmet. They seldom promoted a helmet above $\$ 50$, and most considered the cheaper helmets would 'do the trick', that is, were capable of serving safety as effectively as the more expensive brands. In some shops (8/29) assistants inquired about the type of cycling the customer would undertake, and then guided her towards the helmets considered more appropriate for this activity.

The inner city specialist shops stocked a greater range of styles and prices of helmet, and were eager to promote the extra advantages of helmets in the upper price range. The advantages proposed included lightness, ventilation, aerodynamic styling, stronger construction, and comfort.

In general stores helmets were of the budget variety. Several stores had 'bargain' helmets (sold without extra padding) and 'special' priced helmets. Assistants often pointed out the latest reductions in prices or any 'specials' that were available. They rarely made any inquiries about the type of cycling intended, and when they did, all the helmets available were considered appropriate.

\section{MANNER OF ASSISTANTS}

In the suburban specialist shops assistants were usually approachable and pleasant. As the shops were not usually very busy these assistants attended to the customer throughout the entire selection time. In inner city specialist shops assistants were often less obliging with their time and were more likely to appear bored or impatient with inquiries. Assistants in the general stores were mostly friendly and pleasant but appeared bemused when asked for assistance. Several admitted knowing nothing about cycle helmets and spent little time assisting the customer.

\section{Discussion}

In the years leading up to compulsory wearing of helmets in New Zealand there was a significant increase in the portion of cyclists wearing helmets. The percentage of serious head injuries among bicyclists has, however, remained relatively constant. Inappropriate or inadequate wearing of helmets may be one explanation and this study has explored whether purchasers of helmets are being correctly advised about their use.

The findings indicate that varying levels of advice and practical skills in fitting helmets are offered in the retail shops. In only a minority of 
shops was the advice given of an adequate standard when judged by safety criteria set for the study. In general, the assistants in specialist cycle shops were better informed and gave more adequate advice than those in department stores.

Three factors underpin this situation. First, appropriate attention to the retailing of cycle helmets is difficult in general department stores. Adequate attention from assistants is precluded by heavy demands of space and by requirements to attend to a very wide range of non-cycling merchandise. Second, there is little information available directly to the purchaser, resulting in greater reliance on the expertise of the assistant. Given the turnover and varied abilities and experience of assistants, this is not ideal. Stepby-step advice on how to select and fit a helmet should be prominently displayed in all stores. This would act as a checklist for both retailers and purchasers. Thirdly, adhesive pads are frequently recommended as a solution to fitting a helmet. This is not in accordance with Land Transport Safety Authority advice to utilise the thinnest possible padding. Appropriate use of padding and safety under impact needs further research.

The findings of this study suggest the need for wide consultation, particularly with the cycle retailers and policy groups, to address the problem of how best to ensure cycle helmet suitability.

The findings reported here are of concern in a wider context. Are the standards of advice offered similar for other consumer safety items? While we cannot answer that in a definitive manner we note that a New Zealand study concerned with the flammability of children's nightclothes reported high levels of insufficient knowledge about fabric flammability among retail assistants selling fabrics for children's nighclothes. $^{5}$ We also note that there is an increasing trend in New Zealand from specialist shops to large departmental chain stores. In many instances staff in these stores are rotated within various departments and thus have limited opportunity to develop knowledge on critical safety aspects of consumer products.

This is a particular concern in those instances where these chains have the largest market share for a product and where it is more likely that the prospective purchaser has less knowledge about the product and the primary consideration is price. One option in the present context would be to restrict helmet sales to specialist shops and to improve retail advice in these. This, however, would miss the majority of opportunities, which probably occur in chain stores, to sell a helmet with each purchase of a bicycle. Identifying incentives for all retailers to provide better advice represents a major challenge for the injury prevention community when the product in question, such as a cycle helmet, can be purchased for as little as $\$ 20$.

We are grateful to the Land Transport Safety Authority (New Zealand) for funding this study. The first author was funded on Training Fellowship from the New Zealand Health Research Council and the second author was supported by a Summer Studentship from the Department of Public Health and General Practice, Christchurch School of Medicine. The Injury Prevention Research Unit is supported by the Health Research Counci of New Zealand and the Accident Rehabilitation and Compensation Insurance Corporation.

1 New Zealand Government. Traffic regulations. Amendment No 24. Wellington: New Zealand Government, 1976.

2 Langley J. Purchasing a bicycle helmet in New Zealand: the genesis of a research study. Injury Prevention 1995; 1: 52.

3 Land Transport Safety Authority. Ride with a Wrap NC 182. Wellington: Land Transport Safety Authority, September 1993.

4 Siedel J. Ethnograph, a textual analysis package. Melbourne: La Trobe University, 1994.

5 McLoughlin E, Langley JD, Laing RM. Prevention of children's burns: legislation and fabric flammability. $N Z$ Med f 1986; 99: 804-7. 